\title{
Wheat flour sensitisation and airways disease in urban bakers
}

\author{
M G PRICHARD, G RYAN, AND A W MUSK
}

From the Department of Respiratory Medicine, Sir Charles Gairdner Hospital, Nedlands, Western Australia 6009

\begin{abstract}
A total of 176 bakers and 24 subjects employed as bread slicers and wrappers were studied to examine the effect of occupational category on respiratory symptoms, ventilatory capacity, non-specific bronchial reactivity, and prick skin test responses to wheat and common allergens. Bakers had a greater prevalence of attacks of wheeze and dyspnoea and more frequently considered that work affected their chests than did slicers and wrappers. Bakers with a history of asthma with onset since starting work in a bakery had a greater prevalence of chronic cough and sputum, increased bronchial reactivity, and positive prick skin test responses to wheat and common allergens than other bakers. There was a significant association between the frequency of positive prick skin tests to wheat and common allergens, suggesting that prior atopy facilitates sensitisation to cereal antigens. The frequency of positive prick skin responses to common allergens, however, declined with increasing baking duration whereas the frequency of positive skin responses to wheat increased with increasing baking duration, suggesting that sub: jects who were sensitised to common allergens were leaving the industry whereas subjects who stayed in the industry increased their risk of developing sensitisation to wheat. Oven handlers had a greater prevalence of attacks of wheeze and dyspnoea and more frequently considered that work affected their chests than either dough makers or general bakers. They also had a greater prevalence of positive prick skin test responses to wheat than dough makers or general bakers. Oven handlers also had a lower mean standardised casual $\mathrm{FEV}_{1}$ than either general bakers or dough makers. Thus oven handlers appear to have a greater risk of developing respiratory allergy and airflow obstruction than bakers in other occupational catergories.
\end{abstract}

Rhinitis and asthma are known to be related to baking. ' Both have been shown to be IgE mediated ${ }^{2}$ and numerous potential allergens have been implicated: wheat and other cereals, ${ }^{1-6}$ grain weevil, ${ }^{7}$ dust mite, ${ }^{8}$ Alternaria and Aspergillus organisms, ${ }^{9}$ and dough improvers. ${ }^{1}$ Of these, wheat is the most frequently recognised source of antigen shown. ${ }^{11} 11$ Sensitisation appears to be related to the intensity and duration of exposure in the industry ${ }^{3}$ as well as to host factors such as a personal or family history of allergic respiratory disease. ${ }^{12}$ Since the intensity of exposure to cereal flour may vary in different areas of the bakery, ${ }^{2}$ job assignment in the bakery may possibly determine the level of exposure and thus

Received 17 October 1983

Accepted 14 November 1983 the prevalence rates of indices of respiratory disease. We examined the prevalence rates of respiratory symptoms, positive skin test responses to cereals and common allergens, impairment of ventilatory capacity, and increased non-specific bronchial reactivity in metropolitan bakers in Perth, Western Australia. In order to determine which exposure factors relate to the rates of respiratory disease, the measures of disease were examined in different occupational subgroups and in relation to duration of employment.

\section{Subjects}

We studied 200 men from 18 metropolitan bakeries. They included 176 bakers and 24 subjects employed only in slicing and wrapping bread. They rep450 
resented $90 \%$ of all bakers in the Perth metropolitan area. Bakery employees engaged only to deliver bread were not included. Sixteen eligible subjects declined to participate in the study and two were excluded due to incomplete data. One female baker and 22 female bread slicers were excluded from analysis. The mean age of the bakers was 35.2 years (range 15-64) and the mean height was $174.8 \mathrm{~cm}$ (range 152-194). The mean age of the bread slicers was 39.6 years (range 23-58) and the mean height was $173.5 \mathrm{~cm}$ (range 161-194).

Subjects were classified according to their job assignments in the bakeries. At the time of the study most of the bakers $(68 \%)$ worked in specialist tasks in three large automated bakeries. They were categorised as "manager or supervisor," "preparer of ingredients," "dough maker," "oven handler," and "slicer and wrapper." Other bakeries were small and less automated. Employees in such bakeries were involved in all aspects of the baking process and were classified as "general bakers." To examine the effect of occupational subgroups on indices of respiratory disease only general bakers, dough makers, and oven handlers who had worked in their current specialty for at least five years were compared. Dough makers and preparers of ingredients were combined because both groups were involved in product preparation for baking and many performed both tasks.

\section{Methods}

All bakers were tested at about the same time of day (4-8 am) at their place of work towards the end of their working shift. Studies were performed in the middle of the working week during spring and summer.

\section{RESPIRATORY SYMPTOMS}

All subjects completed a physician administered questionnaire based on the British Medical Research Council questionnaire on respiratory symptoms. ${ }^{13}$ A detailed occupational history was also obtained. "Chronic bronchitis" was defined as cough productive of sputum on most days for at least three months of each year for two or more consecutive years. ${ }^{14}$ Attacks of wheeze and dyspnoea were recorded if subjects responded positively to the question: "Have you ever had attacks of shortness of breath with wheezing?" Bakers were asked if they believed "that work in the bakery had affected their chests" and if they had "ever been told by a physician that they had asthma." Those with a history of asthma were further subdivided into those with asthma since childhood and those in whom the onset of asthma had occurred only since they had started baking. "Work related asthma" was defined as the presence of attacks of wheeze and dyspnoea in subjects who believed that work affected their chests. This group included all those subjects with physician diagnosed asthma that had started since they had become bakers. "Seasonal rhinitis" was recorded if subjects responded positively to the questions: "Do you often sneeze or get an itchy, running nose?" and "Do you get this more often during any particular season?"

\section{PULMONARY FUNCTION}

Forced expiratory volume in one second $\left(\mathrm{FEV}_{1}\right)$ and forced vital capacity were recorded on a dry bellows spirometer (Vitallograph). The mean of the best two measurements of FEV ${ }_{1}$ from three technically satisfactory attempts after one or more practice attempts was taken for analysis and corrected to BTPS. ${ }^{15}$ Standardised $\mathrm{FEV}_{1}$ values were calculated for each subject using the age and height regression of the whole group and correcting the measured volume to the mean age and height of all subjects.

Bronchial reactivity was assessed using doubling doses of methacholine aerosol administered every 90 seconds from a hand operated calibrated Devilbiss No 40 nebuliser. The starting dose was $0.04 \mu \mathrm{mol}$ in subjects with an FEV, less than $60 \%$ of the predicted value or a history of asthma and $0 \cdot 15 \mu \mathrm{mol}$ for other subjects. ${ }^{16}$ The challenge was terminated when the $\mathrm{FEV}_{1}$ fell by more than $20 \%$ from the initial (post saline) value or a total cumulative dose of $30 \mu \mathrm{mol}$ of methacholine had been administered. Reactivity was expressed as the cumulative dose producing a $20 \%$ fall in $\mathrm{FEV}_{1}$ (PD20).

Prick skin tests were performed with a range of baking related and common allergens. Extracts of whole wheat, rye, barley and oats, bakers' yeast, grass pollens, house dust, and animal danders were obtained from Hollister-Stier (Spokane, Washington). House dust mite (Dermatophagoides pteronyssinus) extract was obtained from the Australian Commonwealth Serum Laboratories and wheat flour extracts from the Wheat Research Institute of ' the Australian Commonwealth Scientific and Industrial Research Organization. Histamine in a solution of $1 \mathrm{mg} / \mathrm{ml}$ (John Bull Laboratories, Victoria, Australia) was used as a positive control and the Hollister-Stier diluent as a negative control. The wheat flour extracts were supplied as a powder and made up to concentrations of $1 \mathrm{mg} / \mathrm{ml}$ and $0.1 \mathrm{mg} /$ $\mathrm{ml}$ in $50 \%$ glycerine. For all skin tests a weal of $3 \mathrm{~mm}$ or more and greater than the negative control was measured as positive. "Atopy" was defined as the presence of a positive prick skin response to at least one common allergen. ${ }^{17}$ 
STATISTICAL METHODS

Continuous variables were compared using an unpaired $t$ test. Comparisons of categorical variables used the chi-square test except if the expected values were less than five, when Fisher's exact test was used. ${ }^{18}$

\section{Results}

The group of 24 men employed as slicers and wrappers who had never worked as bakers were considered to be a suitable comparison group because they were less exposed to cereal flour by virtue of their assignment and location in the bakery. They were of similar age, height, and smoking habit to the 176 subjects employed directly in the baking process (table 1). There was a greater prevalence of attacks of wheeze and breathlessness in bakers and more

Table 1 Characteristics of bakers compared with those of slicers and wrappers

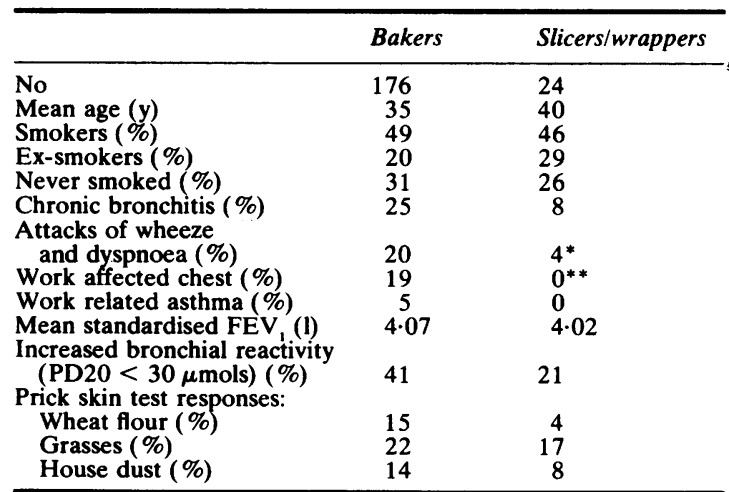

Statistical significance of difference between bakers and slicers and wrappers ${ }^{*} p<0.05,{ }^{* *} p<0.01$.

Table 2 Characteristics of bakers with work related asthma

\begin{tabular}{llc}
\hline & $\begin{array}{l}\text { Work related } \\
\text { asthma }\end{array}$ & Other bakers \\
\hline No & 20 & 156 \\
Mean age (y) & 32 & 34 \\
Smokers (\%) & 45 & 49 \\
Ex-smokers (\%) & 15 & 21 \\
Never smoked (\%) & 40 & 30 \\
Chronic bronchitis (\%) & $60^{* * *}$ & 21 \\
Mean standardised FEV (1) & $3 \cdot 95$ & $4 \cdot 09$ \\
Increased bronchial reactivity & & 37 \\
$\quad$ PD20 < 30 $\mu$ mols) (\%) & $75^{* * *}$ & 10 \\
Prick skin test responses: & & 19 \\
$\quad$ Wheat flour (\%) & $50^{* * *}$ & 12 \\
$\quad$ Grasses (\%) & $35^{* * *}$ & $35^{* * *}$ \\
\hline
\end{tabular}

Statistical significance of difference between bakers with work related asthma and other bakers ${ }^{* * *} p<0.001$.
Table 3 Relationship between prick skin test responses to wheat and co-existing indices of common allergy

\begin{tabular}{lll}
\hline & \multicolumn{2}{l}{ Wheat prick skin test response } \\
\cline { 2 - 3 } & Positive (\%) & Negative (\%) \\
\hline $\begin{array}{l}\text { Positive prick skin test } \\
\text { response to common allergens }\end{array}$ & 69 & $35^{* * *}$ \\
\begin{tabular}{l} 
Seasonal rhinitis \\
\hline
\end{tabular} & 35 & $15^{*}$ \\
\hline
\end{tabular}

Statistical significance of difference between bakers according to their prick skin test response to wheat ${ }^{*} p<0.05,{ }^{* * *} p<0.001$.

bakers believed that work affected their chests than slicers and wrappers. A similar proportion of bakers and slicers and wrappers had had asthma in childhood. None of the slicers and wrappers had developed asthma since starting work in the bakery.

Bakers tended to have increased bronchial reactivity (PD20 $<30 \mu \mathrm{mol}$ ) and more positive prick skin test responses to wheat and other cereals than slicers and wrappers. These differences, however, were not statistically significant. There was a similar distribution of prick skin test responses to grasses and house dust in bakers and slicers and wrappers.

Twenty bakers fulfilled the definition of work related asthma. They were of similar age and smoking habit to other bakers (table 2). Sixty per cent of bakers with work related asthma fulfilled the criteria for chronic bronchitis, a significantly greater prevalence than in other bakers. Although there was no difference between the height and age standardised FEV 1 between the two groups, bakers with work related asthma more frequently had increased bronchial reactivity (PD20 $<30 \mu \mathrm{mol})$ and positive prick skin tests to wheat flour and common allergens than other bakers.

There was a significantly greater prevalence of seasonal rhinitis and coexisting positive prick skin test responses to common allergens in bakers who reacted to wheat on skin testing than in those who did not react to wheat (table 3 ). There was also a positive relationship between duration of baking and frequency of positive prick skin test responses to

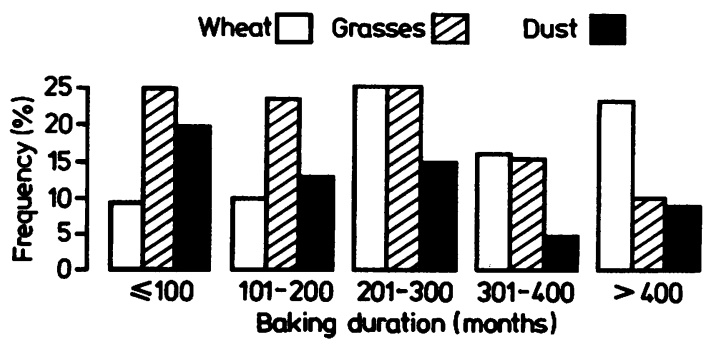

Frequency of positive prick skin responses to wheat, grasses, and house dust by duration of baking. 
Table 4 Skin tests and pulmonary function in occupational subgroups

\begin{tabular}{llll}
\hline & $\begin{array}{l}\text { Oven } \\
\text { handlers }\end{array}$ & $\begin{array}{l}\text { General } \\
\text { bakers }\end{array}$ & $\begin{array}{l}\text { Dough } \\
\text { makers }\end{array}$ \\
\hline No & 16 & 29 & 17 \\
Mean age (y) & 49 & 44 & 41 \\
Smokers (\%) & 44 & 59 & 53 \\
Ex-smokers (\%) & 25 & 24 & 24 \\
Never smoked (\%) & 31 & 17 & 24 \\
$\begin{array}{l}\text { Attacks of wheeze } \\
\quad \text { and dyspnoea (\%) }\end{array}$ & 44 & $14^{*}$ & 24 \\
$\begin{array}{l}\text { Work affects chest (\%) } \\
\text { Prick skin test responses: }\end{array} \quad 31$ & 17 & $6^{*}$ \\
$\quad \begin{array}{l}\text { Wheat flour (\%) } \\
\text { Grasses (\%) }\end{array}$ & 44 & 17 & $0^{* *}$ \\
$\quad \begin{array}{l}\text { House dust (\%) } \\
\text { Mean standardised FEV (1) }\end{array}$ & 38 & 17 & 12 \\
Increased bronchial reactivity & $3 \cdot 54$ & $4 \cdot 05^{*}$ & 12 \\
$\quad$ (PD20 < 30 $\mu$ mols) (\%) & 56 & 41 & 29 \\
\hline
\end{tabular}

Statistical significance of difference from oven handlers ${ }^{*} p<0.05$, ${ }^{* *} \mathrm{p}<0.01,{ }^{* * *} \mathrm{p}<0.001$.

wheat antigens in bakers, whereas the frequency of positive prick skin test responses to grasses and house dust decreased with increasing baking duration (figure).

The occupational subgroups were similar in age and smoking habit (table 4). Nevertheless, a group of 16 oven handlers had a greater prevalence of .attacks of wheeze and breathlessness and more frequently considered that work in the bakery affected their chests than did a group of 29 general bakers or a group of 17 dough makers. Standardised FEV was significantly lower in oven handlers than in dough makers or general bakers. Oven handlers also tended to have a greater prevalence of increased bronchial reactivity than general bakers and dough makers, although this was not statistically significant. Additionally, oven handlers more frequently reacted to wheat and other cereals on prick skin testing than dough makers.

\section{Discussion}

In the baking industry symptoms of work related asthma are common and appear to relate to exposure to ingredients of bread. ${ }^{10}$ Bakers more frequently admitted to attacks of wheeze and dyspnoea and considered that work affected their chests than slicers and wrappers. They showed a tendency towards a greater prevalence of positive prick skin tests responses to wheat antigens, and those with work related attacks of wheeze and dyspnoea had a significantly greater prevalence of positive prick skin test responses to wheat antigens than other bakers. Pre-existing atopy may have predisposed the bakers to more frequent wheat flour sensitisation and respiratory disease than the less exposed slicers and wrappers. ${ }^{12}$ Part of the excess frequency of positive prick skin responses to common allergens may also be explained by cross reactivity between cereal and grass antigens. ${ }^{19}$ Nevertheless the more obvious explanation for the findings is that bakers have work related allergic respiratory disease ("bakers' asthma").

Symptoms of wheeze and dyspnoea that were work related were associated with increased nonspecific bronchial reactivity (though not with a lower standardised casual FEV ). This result is in keeping with a previous study showing a higher frequency of positive acetylcholine tests in bakers with proved occupational disease than in unselected bakers or controls. ${ }^{3}$ Both studies support the concept that wheeze and dyspnoea are related to non-allergic bronchial reactivity in bakers' asthma as in other forms of allergen induced asthma. ${ }^{20}$ The higher prevalence of positive skin tests to wheat in bakers with work related asthma indicates an association between exposure and symptoms and suggests that wheat is implicated in the pathogenesis of asthma in bakers.

The greater prevalence of seasonal rhinitis and co-existing positive prick skin test responses to common allergens in bakers who reacted to wheat on skin testing than in those who did not react to wheat supports earlier evidence that atopy may facilitate sensitisation to cereal antigens. ${ }^{12}$ The frequency, however, of positive prick skin test responses to common allergens (grasses and house dust) declined with increasing duration of baking whereas the frequency of positive skin responses to wheat increased with increasing baking duration. Thus it appears that subjects with sensitivity to common allergens may be selectively leaving the industry (possibly because of the development of work related symptoms) whereas the surviving, less atopic population continues to develop sensitivity on exposure to wheat flour at work. A prospective study in the industry has been designed to evaluate this possibility.

Oven handlers had a greater prevalence of indices of respiratory disease than either dough makers or general bakers, despite the observation that doughmakers are more exposed to airborne, uncooked flour. The lower mean standardised $\mathrm{FEV}_{1}$ was not explained by any difference in smoking habit. This may represent either the presence of industrial bronchitis with airflow obstruction or the result of recent occupational exposure to antigen in sensitised individuals. ${ }^{21}$ Since the measurement was a casual FEV and not necessarily the best (postbronchodilator) value these data alone cannot distinguish between these two causes. The greater prevalence of other indices of disease in oven handlers, however, suggests that they may have exposure to more 
potent allergens in wheat which are responsible for respiratory disease and skin reactivity. This may be attributed to alteration in respirability or antigenicity during cooking. Thus oven handlers may be at greater risk of developing symptoms and airflow obstruction at work than other bakers. Further attention should be paid to characterising the exposures of this group in efforts to control respiratory disease in bakers.

We thank the Bread Manufacturers' Association of Western Australia for its help with the conduct of the study and for meeting the costs of the skin testing materials. RAST measurements were performed by the Wheat Research Institute of the Australian Commonwealth Scientific and Industrial Research Organization, North Ryde, NSW, Australia. The help of Dr David Hoffman, Sr Sue Morey, and Sr Sandra Peach in collecing the data and Ms L Bingle and Ms A Pickard in the typing of the manuscripts is gratefully appreciated.

\section{References}

' Bonnevie P. Occupational allergy in bakery. In: Stenfert-Kroese WF, ed. European Academy of Allergy, occupational allergy. Springfield, Ill. C Thomas, 1958:161-8.

${ }^{2}$ Napolitano J, Weiss NS. Occupational asthma of bakers. Ann Allergy 1978; 40:258-61.

${ }^{3}$ Thiel H, Ulmer WT. Bakers' asthma: development and possibility for treatment. Chest 1980;78 (suppl):400-5.

${ }^{4}$ Block G, Kijek K, Chan H, Tse KS, Chan-Yeung M. Pathogenic mechanisms in bakers asthma. Am Rev Respir Dis 1982;125(suppl):74. (Abstract American Thoracic Society meeting.)

${ }^{5}$ Herxheimer $\mathrm{H}$. The skin sensitivity to flour of baker's apprentices. Acta Allergol 1973;28:42-9.
' Hendrick DJ, Davies RJ, Pepys J. Bakers' asthma. Clin Allergy 1976;6:241-50.

' Frankland AW, Lunn JA. Asthma caused by the grain weevil. $\mathrm{Br}$ $J$ Ind Med 1965;22:157-9.

${ }^{8}$ Popescu IG, Ulmeanu V, Muraniu D. Atopic and non-atopic sensitivity in a large bakery. Allergol Immunopathol 1981;9:307-12.

9 Klaustermeyer WB, Bardana EJ, Hale FC. Pulmonary hypersensitivity to alternaria and aspergillus in bakers' asthma. Clin Allergy 1977; 7:227-33.

${ }^{10}$ Anonymous. Bakers' asthma (Editorial). $\mathrm{Br} \mathrm{Med} J$ 1981;282:678.

"Popa V, George SAL, Gavanoscu O. Occupational and nonoccupational respiratory allergy in bakers. Acta Allergol 1970;25:159-77.

12 Jarvinen KAJ, Pirila V, Bjorksten F, Kerskinen H, Lentinen M, Stubb S. Unsuitability of bakery work for a person with atopy: a study of 234 bakery workers. Ann Allergy 1979;42:192-5.

${ }^{13}$ Bouhuys A. Breathing: physiology, environment and lung disease. New York: Grune and Stratton; 1974:295-300, 307-13.

${ }^{14}$ American Thoracic Society. Statement on definitions and classification of chronic bronchitis, asthma and pulmonary emphysema. Am Rev Respir Dis 1962;85:762-8.

is Knudson RJ, Slatin RC, Lebowitz MD, Burrows B. The maximal expiratory flow-volume curve: normal standards, variability and the effects of age. Am Rev Respir Dis 1976;113:587-600.

${ }^{16}$ Woolcock AJ, Yan K, Anderson SD, Stuckey M. Bronchial responsiveness in adult population. Aust NZJ Med (in press). (Abstract Thoracic Society of Australia Meeting.)

17 Woolcock AJ, Colman MH, Jones MW. Atopy and bronchial reactivity in Australian and Melanesian populations. Clin Allergy 1978;8:155-64.

${ }^{18}$ Armitage P. Statistical methods in medical research. Oxford: Blackwell Scientific Publications, 1971.

${ }^{19}$ Blands J, Diamant B, Kallos P, Kallos-Deffner L, Lowenstein H. Flour allergy in bakers. Int Arch Allergy Appl Immunol 1976; 52:392-406.

${ }^{20}$ Mink JT, Gerrard JW, Cockcroft DW, Cotton DJ, Dosman JA. Increased bronchial reactivity to histamine in nonsmoking grain workers with normal lung function. Chest 1980;77:2831.

${ }^{21}$ Chan-Yeung M, Wong R, MacLean L. Respiratory abnormalities among grain elevator workers. Chest 1979;75:461-7. 